TITLE:

\title{
Dielectric anisotropy of oven- and air-dried wood evaluated using a free space millimeter wave
}

\section{$\operatorname{AUTHOR}(S)$ :}

Tanaka, Soichi; Fujiwara, Yuko; Fujii, Yoshihisa; Okumura, Shogo; Togo, Hiroyoshi; Kukutsu, Naoya; Mochizuki, Shoji

\section{CITATION:}

Tanaka, Soichi ...[et al]. Dielectric anisotropy of oven- and air-dried wood evaluated using a free space millimeter wave. Journal of Wood Science 2013, 59(5): 367-374

\section{ISSUE DATE:}

2013-10

URL:

http://hdl.handle.net/2433/193013

\section{RIGHT:}

The final publication is available at Springer via http://dx.doi.org/10.1007/s10086-0131341-7.; この論文は出版社版でありません。引用の際には出版社版をご確認ご利用くだ さい。; This is not the published version. Please cite only the published version. 
Original article

\section{Title}

Dielectric anisotropy of oven- and air-dried wood evaluated using a free space millimeter wave*

\section{Author's information}

Soichi Tanaka, Yuko Fujiwara, Yoshihisa Fujii, Shogo Okumura

Graduate School of Agriculture, Kyoto University, Kyoto 606-8502, Japan

Hiroyoshi Togo, Naoya Kukutsu

NTT Microsystem Integration Laboratories, Atsugi 243-0198, Japan

and

Shoji Mochizuki

NTT Access Network Service Systems Laboratories, Tsukuba 305-0805, Japan

\section{Corresponding Author}

Soichi Tanaka

e-mail: stanaka@h3news1.kais.kyoto-u.ac.jp

Tel. +81-75-753-6245; Fax. +81-75-753-6245

\section{Keywords}

Dielectric anisotropy, Density, Dielectric mixture, Millimeter wave, Free space method

* Part of this report was presented at the 62nd Annual Meeting of the Japan Wood Research Society, Sapporo, March 2012. 


\section{Abstract}

To evaluate the dielectric anisotropy caused by wood structure at a millimeter wave frequency of $100 \mathrm{GHz}$, the dielectric parameters for flat-sawn specimens of nine wood species at 0 and $11 \%$ moisture content (MC) were measured using a free space method devised for reducing the multiple reflections under an electric field of millimeter waves parallel to longitudinal and tangential directions of wood, and those in radial direction were estimated using a conventional approximation theory. The dielectric parameters in the tangential and radial directions were almost identical and constantly smaller than those in the longitudinal direction. All the dielectric parameters increased with wood density and were larger at $11 \%$ than $0 \%$ MC. The dielectric parameters in the longitudinal and transverse directions and the dielectric anisotropy between them were well fitted to the regression lines based on a dielectric mixture model composed of pores and dielectric isotropic wood substance, and a parallel capacitor and Lichtenecker's exponential formulas were employed to represent the dielectric parameters of the mixture in the longitudinal and transverse directions, respectively. It was concluded that the dielectric anisotropy at $100 \mathrm{GHz}$ is caused by the pore alignment and that the dielectric parameters are almost unaffected by anatomical structures such as the rays. It was also confirmed that the free space method was effective for the measurement of the dielectric parameters for the flat-sawn specimens. 


\section{Introduction}

A millimeter wave (MMW) technique, dealing with electromagnetic waves in the 30 to $300 \mathrm{GHz}$ frequency range, has recently been applied to nondestructive evaluation (NDE) of wood [1-3]. This technique is inexpensive, non-contact, non-invasive, compact, and easy to use in the wood industry. It is especially attractive because it has higher resolution than the conventional microwave technique [4-13] in the 3 to 30 $\mathrm{GHz}$ frequency range.

In our previous study [3], we demonstrated the dependence of the MMW transmittance of hinoki on its grain direction and pointed out that this was caused by the dielectric anisotropy, which refers to the difference in the dielectric parameters (or complex permittivity) in the longitudinal (L), tangential (T), and radial (R) directions [14-29]. A number of researchers have examined the dielectric anisotropy at frequencies below $1 \mathrm{GHz}$ by regarding wood as a dielectric mixture, or a porous structure composed of air and wood substance [17, 18, 20, 23, 29]. Norimoto and Yamada [23] examined the relation of the dielectric parameters of wood to its density/porosity and concluded that the dielectric anisotropy of wood was caused by the dielectric anisotropy of wood substance and/or the alignment of the pores. The dielectric anisotropy of wood in the MMW frequency range, however, has never been examined with the exception of our research [3] and thereby its cause is as yet obscure. Of major interest, both fundamentally and practically, are whether wood substance is an isotropic or anisotropic dielectric material and how the pore alignment is formulated in the MMW frequency range.

The primary purpose of this study was to evaluate the dielectric anisotropy caused by wood structure at a representative MMW frequency of $100 \mathrm{GHz}$. For this purpose, the dielectric parameters were obtained for flat-sawn specimens of softwood and ring- and diffuse-porous hardwood species of different thicknesses at 0 and 11\% moisture content (MC), and the relation between the parameters and wood density was examined using a dielectric mixture model in consideration of the dielectric isotropy/anisotropy of wood substance and the formulation of the pore alignment.

It has been reported that the dielectric parameters measured using a free space method were degraded by the multiple reflections [4, 30, 31]. In this study, the dielectric parameters were measured using a free space method with a measurement system that was devised for reducing the multiple reflections, and they were compared with those obtained by a conventional waveguide method [26, 32] to examine the validity of the measurements. 


\section{Theoretical background}

\section{Dielectric parameters in a free space method}

The behavior of a linearly polarized electromagnetic wave in wood is generally represented as a function of the amplitude and phase of an electric field [3, 4, 8, 11-13]. The electric field $\boldsymbol{E}$ parallel to the $\mathrm{L}$ or $\mathrm{T}$ direction is affected by the dielectric parameters of wood in the L or T direction, respectively [3, 11-13]. Assuming that wood is homogeneous, the electric field, $E_{\mathrm{L}}$ or $E_{\mathrm{T}}$, in the $\mathrm{L}$ or $\mathrm{T}$ direction, of the MMW propagated through a flat-sawn (large surface parallel to LT plane, LT) specimen along the R direction is formulated as follows:

$$
\begin{aligned}
E_{m} & =E_{0} \exp \left\{\mathrm{i}\left(\beta_{m}+\mathrm{i} \frac{1}{2} \alpha_{m}-\frac{2 \pi}{\lambda}\right) d\right\} \\
& =E_{0} \exp \left\{\mathrm{i} \frac{2 \pi}{\lambda}\left(\sqrt{\varepsilon_{m}^{\prime}\left(1+\mathrm{i} \tan \delta_{m}\right)}-1\right) d\right\},
\end{aligned}
$$

where subscript $m$ represents symbols $L$ and $T$, and $E_{0}$ is the incident electric field, $\lambda$ is the wavelength of the MMW in air ( $=3 \mathrm{~mm}), d$ is the specimen thickness, $\alpha_{m}, \beta_{m}, \varepsilon_{m}^{\prime}$, and $\tan \delta_{m}$ are the attenuation and phase coefficients, the relative dielectric constant, and the loss tangent ( $\delta_{m}$, loss angle) of the specimen, respectively.

In this study, attenuation $\ln P$ ( $P$, transmittance) and phase shift $\Delta \xi$ of the voltage signals were obtained, and they are related to the attenuation and phase coefficients as follows:

$$
\ln P_{m}=\ln \left|\frac{E_{m}}{E_{0}}\right|=-\frac{1}{2} \alpha_{m} d, \quad \Delta \xi_{m}=\left(\beta_{m}-\frac{2 \pi}{\lambda}\right) d .
$$

The dielectric parameters, $\varepsilon_{m}^{\prime}$ and $\tan \delta_{m}$, are derived from the second and the third members of Eq. (1):

$$
\varepsilon_{m}^{\prime}=\frac{\lambda^{2}}{4 \pi^{2}}\left(\beta_{m}^{2}-\frac{\alpha_{m}^{2}}{4}\right), \quad \tan \delta_{m}=\frac{4 \beta_{m} \alpha_{m}}{4 \beta_{m}^{2}-\alpha_{m}^{2}},
$$

and they constitute the complex permittivity: $\varepsilon_{m}=\varepsilon^{\prime} m\left(1+\mathrm{i} \tan \delta_{m}\right)$.

The complex permittivity in the R direction, $\varepsilon_{\mathrm{R}}$, can be estimated using the measured permittivities, $\varepsilon_{\mathrm{L}}$ and $\varepsilon_{\mathrm{T}}$, and a theory based on some assumptions [26], where $\varepsilon_{\mathrm{R}}$ is considered to be affected by the complex permittivity of the rays in their longitudinal direction, which is regarded to be approximately equal to $\varepsilon_{\mathrm{L}}$, and that of the axial elements in their transverse direction, which is regarded to be approximately equal to $\varepsilon_{\mathrm{T}}$. Assuming that the contributions of the rays and axial elements to $\varepsilon_{\mathrm{R}}$ are in proportion to their volume fractions, $v_{\mathrm{r}}$ and $1-v_{\mathrm{r}}$, respectively, $\varepsilon_{\mathrm{R}}$ is estimated as follows:

$$
\varepsilon_{\mathrm{R}}=\left(1-v_{\mathrm{r}}\right) \varepsilon_{\mathrm{T}}+v_{\mathrm{r}} \varepsilon_{\mathrm{L}},
$$

where $\varepsilon_{\mathrm{R}}$ is also represented as $\varepsilon^{\prime} \mathrm{R}\left(1+\mathrm{i} \tan \delta_{\mathrm{R}}\right)$.

\section{Dielectric mixture model}

Wood is composed of porous wood cells such as the tracheids, fibers, and ray cells and thereby can be regarded as a dielectric mixture with the pores elongated in the $\mathrm{L}$ and $\mathrm{R}$ directions and aligned orderly in wood substance composed of cellulose of oriented molecule, hemicellulose, lignin, and bound water. The 
first question about this model is which of the two factors, the alignment of the pores and the dielectric anisotropy of wood substance, causes the dielectric anisotropy of wood [17-20, 23, 25, 29]. Norimoto and Yamada [23] concluded that the dielectric anisotropy of oven-dried wood is caused by both of them in the low frequency range and only by the pore alignment in the high frequency range. According to their conclusion, it is expected that the dielectric anisotropy of oven-dried wood at a frequency of $100 \mathrm{GHz}$ is caused only by the pore alignment and that wood substance is a dielectric isotropic material. For air-dried wood ( $\mathrm{MC}=11 \%$ ), wood substance with bound water is assumed to be also isotropic.

The second question is how the pore alignment is formulated as a function of the wood volume fraction, or wood density. A parallel capacitor formula is generally used for the complex permittivity in the L direction, $\varepsilon_{\mathrm{L}}[17,18,20,23]$, and is formulated as follows:

$$
\varepsilon_{\mathrm{L}}=\varepsilon_{\mathrm{L}}\left(\varepsilon_{\mathrm{wS}}^{\prime}, \delta_{\mathrm{wS}}, v_{\mathrm{wS}}\right)=1-v_{\mathrm{wS}}+v_{\mathrm{wS}} \varepsilon_{\mathrm{wS}},
$$

where $\varepsilon^{\prime}$ ws, $\delta_{\mathrm{WS}}, \varepsilon \mathrm{ws}$, and $v_{\mathrm{Ws}}$ represent the relative dielectric constant, loss angle, complex permittivity, and volume fraction of wood substance, respectively. There is a relation among $\varepsilon^{\prime}$ Ws, $\delta_{\mathrm{WS}}$, and $\varepsilon$ Ws as $\varepsilon_{\mathrm{Ws}}=\varepsilon^{\prime}$ Ws $\left(1+\mathrm{i} \tan \delta_{\mathrm{ws}}\right)$. The volume fractions of wood substance in a wood specimen with an oven-dry density of $\rho_{0}$ are estimated as $v_{\mathrm{WS}}=\rho_{0} / 1.50$ and $v_{\mathrm{WS}}=0.760 \rho_{0} /\left(1+0.094 \rho_{0}\right)$ at 0 and $11 \% \mathrm{MC}$, respectively [29]. It is difficult to relate the complex permittivities in the $\mathrm{R}$ and $\mathrm{T}$ directions to the wood volume fraction because the capacitor models in these directions are more complicated and require the information about the anatomical structure of wood [20]. This was solved by introducing the complex permittivity in the transverse $(\perp)$ direction, $\varepsilon_{\perp}=\left(\varepsilon_{\mathrm{T}}+\varepsilon_{\mathrm{R}}\right) / 2\left(=\varepsilon_{\perp}^{\prime}\left(1+\mathrm{i} \tan \delta_{\perp}\right)\right)$ into a model [29]. However, this model was not based on the principle of the electromagnetics. In this study, a Lichtenecker's exponential formula [33-35] was used to explain the complex permittivity in the $\perp$ direction, because it was established from the principle of the electromagnetics and some assumptions [36]. This is formulated as follows:

$$
\varepsilon_{\perp}=\varepsilon_{\perp}\left(\varepsilon_{\mathrm{WS}}^{\prime}, \delta_{\mathrm{WS}}, v_{\mathrm{WS}}, k\right)=\left(1-v_{\mathrm{WS}}+v_{\mathrm{WS}} \varepsilon_{\mathrm{WS}}^{k}\right)^{1 / k}
$$

where $k$ represents the coefficient varying from -1 to 1 and is associated with the pore alignment along the direction of the external electric field. 


\section{Experimental}

\section{Specimens}

Flat-sawn (LT) specimens, $100 \mathrm{~mm}$ square and 2 to $8 \mathrm{~mm}$ thick, were prepared from the sound heartwood of softwoods, hinoki (Chamaecyparis obtusa), sugi (Cryptomeria japonica), and akamatsu (Pinus densiflora); ring-porous hardwoods, kiri (Paulownia tomentosa), kuri (Castanea crenata), and keyaki (Zelkova serrata); and diffuse-porous hardwoods, tochinoki (Aesculus turbinata), buna (Fagus crenata), and isunoki (Distylium racemosum). Their oven-dry densities are summarized in Table 1 with their volume fractions of the rays (literature values [37]). No quarter-sawn (LR) specimen was used in this study since the MMW may possibly be scattered by their annual rings with a comparable width to the wavelength, $3 \mathrm{~mm}$.

All the specimens were stored over a saturated $\mathrm{NaBr}$ solution in a desiccator at $27.5^{\circ} \mathrm{C}$ to be conditioned at $11 \%$ MC. After the measurement they were dried to a relatively constant weight at $105^{\circ} \mathrm{C}$ and provided for the succeeding measurement at $0 \%$ MC. Incidentally, the average MCs of specimens conditioned at 0 and $11 \%$ MC were 0.4 and 11\%, respectively, after the measurement of their dielectric parameters.

\section{Apparatus and measurement}

Figure 1 shows an experimental set-up of a MMW measurement system arranged in a right-handed Cartesian coordinate system $(x, y, z)$. A MMW signal of $100 \mathrm{GHz}$ with an average output power of $10 \mathrm{~mW}$ was oscillated in a Gunn diode and divided into two signals, measurement and reference, by a directional coupler. The reference signal was sent to an in-phase/quadrature mixer (IQ-mixer) through a dielectric waveguide. The measurement signal was modulated using a PIN (p-intrinsic-n) diode at a switching frequency of $100 \mathrm{kHz}$ and passed through a phase shifter. The wave linearly polarized in the $y$ direction was transmitted by a conical horn antenna towards the $z$ direction and collimated using a Teflon plano-parabolic lens with a diameter of $80 \mathrm{~mm}$ and a focal length of $33 \mathrm{~mm}$. The wave that passed through the specimen was received by an open-ended rectangular waveguide at $(x, y, z)=(0,0,150 \mathrm{~mm})$ with an inner cross section of $2.54 \mathrm{~mm}$ in the $x$ direction and $1.27 \mathrm{~mm}$ in the $y$ direction and sent to the IQ-mixer, where the in-phase (I) and quadrature $(\mathrm{Q})$ components were discriminated by comparing the measurement and reference signals. The signals from the IQ-mixer were processed into the voltages, $V_{\mathrm{I}}$ and $V_{\mathrm{Q}}$, in a lock-in amplifier. The front face of the waveguide, excluding the aperture, was covered with MMW absorbent material to prevent reflections from the waveguide and the surrounding parts of the apparatus.

The voltages, $V_{\mathrm{I}}$ and $V_{\mathrm{Q}}$, were measured while the phase of the measurement signal, $\varphi$, was being changed from 0 to $2 \pi$ rad at intervals of $\pi / 9$ rad using the phase shifter (Fig. 1 ). The specimen was set so that its surface was parallel to the $x y$-plane and its center was on the $z$-axis. All the measurements were conducted at 22 to $25^{\circ} \mathrm{C}$. 


\section{Results and discussion}

\section{Attenuation and phase coefficients of specimens}

Figure 2 shows the relation of $V_{\mathrm{I}}$ and $V_{\mathrm{Q}}$ to $\varphi$ for hinoki of different thicknesses at $11 \% \mathrm{MC}$ under an electric field of the wave parallel to the $T$ direction. The voltages, $V_{\mathrm{I}}$ and $V_{\mathrm{Q}}$, are formulated as follows:

$$
V_{n}=A_{n}\left\{\cos \left(\varphi+\xi_{n}\right)+r_{n} \cos \left(3 \varphi+\eta_{n}\right)\right\}
$$

where $n$ represents I and $\mathrm{Q}, A_{n}$ and $\xi_{n}$ are the amplitude and phase, respectively, of the measurement signal that passed through the phase shifter only once, and $r_{n}$ and $\eta_{n}$ are the proportion and phase, respectively, of the signal that passed through the phase shifter three times. Equation (7) was fitted to the plots in Fig. 2 by using a least squares method to determine parameters, $A_{\mathrm{I}}, A_{\mathrm{Q}}, \xi_{\mathrm{I}}, \xi_{\mathrm{Q}}, r_{\mathrm{I}}, r_{\mathrm{Q}}, \eta_{\mathrm{I}}$, and $\eta_{\mathrm{Q}}$. The fit was good for all species at $0 \%$ as well as $11 \% \mathrm{MC}$.

Assuming that the $\beta_{m}-2 \pi / \lambda$ in Eq. (2) is proportional to the oven-dry density of the specimen, $\rho_{0}$, the phase shift is in proportion to the product of $d$ and $\rho_{0}$. The relations of $\xi_{\mathrm{I}}$ and $\xi_{\mathrm{Q}}$ to $\rho_{0} d$ for all specimens of all species at 11\% MC are shown in Fig. 3. The phases for the plots surrounded by solid and dotted lines in Fig. 3 should be larger by $2 \pi$ and $4 \pi$ rad, respectively, because the phase of more than $2 \pi$ rad is measured within the limit of $2 \pi$ rad according to the signification of the phase shifter. Thus, the true phases, $\xi_{\text {I }}$ and $\xi_{\text {Q }}^{\prime}$, were obtained by the correction of the apparent phases, $\xi_{\mathrm{I}}$ and $\xi_{\mathrm{Q}}$, and used for the subsequent analysis.

The relations of attenuation, $\ln P\left(\ln P_{\mathrm{L}}, \ln P_{\mathrm{T}}\right)$, and phase shift, $\Delta \xi\left(\Delta \xi_{\mathrm{L}}, \Delta \xi_{\mathrm{T}}\right)$, in the $\mathrm{L}$ and $\mathrm{T}$ directions to specimen thickness, $d$, for hinoki at 11\% MC are shown in Fig. 4. The attenuation and phase shift in Fig. 4 were obtained using the following equations to reduce the influence of the multiple reflections:

$$
\ln P=\ln \left\{\frac{1}{2}\left(\frac{A_{\mathrm{I}}}{A_{\mathrm{I} 0}}+\frac{A_{\mathrm{Q}}}{A_{\mathrm{Q} 0}}\right)\right\}, \quad \Delta \xi=\frac{1}{2}\left\{\left(\xi_{\mathrm{I}}^{\prime}-\xi_{\mathrm{I} 0}^{\prime}\right)+\left(\xi_{\mathrm{Q}}^{\prime}-\xi_{\mathrm{Q} 0}^{\prime}\right)\right\},
$$

where $A_{\mathrm{I} 0}, A_{\mathrm{Q} 0}, \xi_{\mathrm{I} 0}^{\prime}$, and $\xi_{\mathrm{Q} 0}^{\prime}$ represent the values of $A_{\mathrm{I}}, A_{\mathrm{Q}}, \xi_{\mathrm{I}}^{\prime}$, and $\xi_{\mathrm{Q}}^{\prime}$ without a specimen, respectively. The attenuation and phase shift in the $\mathrm{L}$ and $\mathrm{T}$ directions had good linear relations to the thickness. The same findings as above were obtained for the specimens at $0 \% \mathrm{MC}$.

The average values and standard deviations of $\alpha_{\mathrm{L}}, \alpha_{\mathrm{T}}, \beta_{\mathrm{L}}-2 \pi / \lambda$, and $\beta_{\mathrm{T}}-2 \pi / \lambda$ were obtained using Eq. (2) from the slopes of the regression lines in Fig. 4. Figure 5 shows the relations of $\alpha_{\mathrm{L}}, \alpha_{\mathrm{T}}, \beta_{\mathrm{L}}-2 \pi / \lambda$, and $\beta_{\mathrm{T}}$ $-2 \pi / \lambda$ to the oven-dry density, $\rho_{0}$, for all specimens at 0 and $11 \%$ MC, where the error bar represents the standard deviation for each plot. The linear relations of $\beta_{\mathrm{L}}-2 \pi / \lambda$ and $\beta_{\mathrm{T}}-2 \pi / \lambda$ to $\rho_{0}$ for both MCs may support the validity of the correction of phases (Fig. 5(b)). The relations in Fig. 5 were consistent with the findings in our previous study [3], where the values, $\alpha_{\mathrm{L}}=1.3 \mathrm{~cm}^{-1}, \alpha_{\mathrm{T}}=0.6 \mathrm{~cm}^{-1}$, and $\beta_{\mathrm{L}}-\beta_{\mathrm{T}}=1.8 \mathrm{rad} / \mathrm{cm}$, were obtained for LT specimens of hinoki of $0.35 \mathrm{~g} / \mathrm{cm}^{3}$ and $8 \%$ MC using a free space method at $100 \mathrm{GHz}$.

\section{Dielectric parameters of specimens}

The dielectric parameters under an electric field of the MMWs parallel to the $\mathrm{L}$ and $\mathrm{T}$ directions, $\varepsilon_{\mathrm{L}}^{\prime}, \varepsilon^{\prime}$, $\tan \delta_{\mathrm{L}}$, and $\tan \delta_{\mathrm{T}}$, were obtained by substituting the values, $\alpha_{m}$ and $\beta_{m}$, ( $m: \mathrm{L}$ or T), into Eq. (3), and those in the R direction, $\varepsilon_{\mathrm{R}}^{\prime}$ and $\tan \delta_{\mathrm{R}}$, were estimated from Eq. (4) using the volume fractions of the rays, $v_{\mathrm{r}}$, listed in Table 1. Figure 6 shows the relations of the dielectric parameters to the oven-dry density, $\rho_{0}$, for all specimens at 0 and 11\% MC. The plots of the dielectric parameters in the $\mathrm{T}$ and $\mathrm{R}$ directions were almost 
identical and were smaller than those in the $\mathrm{L}$ direction, and all the dielectric parameters increased with $\rho_{0}$ for $0 \%$ MC (Fig. 6(a) and (b)). The plots of the dielectric parameters versus $\rho_{0}$ at $11 \%$ MC (Fig. 6(c) and (d)) showed similar trends to those at $0 \%$, although the dielectric parameters at $11 \% \mathrm{MC}$ were larger than those at $0 \% \mathrm{MC}$ on the whole.

The dotted lines for $\varepsilon^{\prime} \perp$ and $\tan \delta_{\perp}$, which were measured by using a waveguide method (Fig. 6(a) and (b)) and predicted (Fig. 6(c)) [26], were consistent with the plots of $\varepsilon^{\prime}{ }_{\mathrm{T}}$ (or $\varepsilon^{\prime}{ }_{\mathrm{R}}$ ) and $\tan \delta_{\mathrm{T}}$ (or $\tan \delta_{\mathrm{R}}$ ). This indicates that the free space method used in this study may be effective for measuring the dielectric parameters.

The dielectric parameters, $\varepsilon_{\mathrm{L}}^{\prime}, \varepsilon_{\perp}^{\prime}, \delta_{\mathrm{L}}$, and $\delta_{\perp}$, can be related to the oven-dry density of specimens, $\rho_{0}$, as expressions for the real parts and angles of Eqs. (5) and (6). Thus, regression lines in Fig. 6 were obtained so that the sum of squares shown by the following equation was minimized for each MC:

$$
\begin{aligned}
S\left(\varepsilon_{\mathrm{wS}}^{\prime}, \delta_{\mathrm{wS}}, k\right)=\sum_{i}[ & \left|\operatorname{Re}\left\{\varepsilon_{\mathrm{L}}\left(\varepsilon_{\mathrm{WS}}^{\prime}, \delta_{\mathrm{wS}}, v_{\mathrm{WS}, i}\right)\right\}-\varepsilon_{\mathrm{L}, i}^{\prime}\right|^{2} \\
& +\left|\arg \left\{\varepsilon_{\mathrm{L}}\left(\varepsilon_{\mathrm{WS}}^{\prime}, \delta_{\mathrm{wS}}, v_{\mathrm{WS}, i}\right)\right\}-\delta_{\mathrm{L}, i}\right|^{2} \\
& +\left|\operatorname{Re}\left\{\varepsilon_{\perp}\left(\varepsilon_{\mathrm{WS}}^{\prime}, \delta_{\mathrm{WS}}, k, v_{\mathrm{WS}, i}\right)\right\}-\varepsilon_{\perp, i}^{\prime}\right|^{2} \\
& \left.+\left|\arg \left\{\varepsilon_{\perp}\left(\varepsilon_{\mathrm{WS}}^{\prime}, \delta_{\mathrm{wS}}, k, v_{\mathrm{WS}, i}\right)\right\}-\delta_{\perp, i}\right|^{2}\right]
\end{aligned}
$$

where $v_{\mathrm{WS}, i}$ represents the volume fraction of wood substance for the $i$-th species, $\varepsilon^{\prime}{ }_{\mathrm{L}, i}$ and $\varepsilon_{\perp, i}^{\prime}$ are the relative dielectric constants in the $\mathrm{L}$ and $\perp$ directions, respectively, $\delta_{\mathrm{L}, i}$ and $\delta_{\perp, i}$ are the loss angles in the $\mathrm{L}$ and $\perp$ directions, respectively. The black and gray solid regression lines for $\varepsilon_{\mathrm{L}}^{\prime}$ and $\varepsilon_{\mathrm{T}}^{\prime}$ (or $\varepsilon_{\mathrm{R}}^{\prime}$ ), respectively, were well fitted to the experimental plots (Figs. 6(a) and (c)) and those for $\tan \delta_{\mathrm{L}}$ and $\tan \delta_{\mathrm{T}}$ (or $\tan \delta_{\mathrm{R}}$ ) were also fitted to the plots (Figs. 6(b) and (d)).

Table 2 shows the estimated values of $\varepsilon^{\prime}$ ws, $\tan \delta_{\mathrm{ws}}$, and $k$ for 0 and $11 \%$ MC. The estimated values of $k$ for 0 and 11\% MC were close to 1/3, the value reported by Trapp and Pungs [27], who used the Lichtenecker's exponential formula, Eq. (6). However, the relation between the coefficient $k$ and the pore alignment has not been clear [33-36]. A good agreement of the plots with the lines (Fig. 6) may give a clue to solve this problem. The dielectric parameters of wood substance, $\varepsilon^{\prime}$ ws and $\tan \delta$ ws, were larger for $11 \%$ than $0 \% \mathrm{MC}$, particularly $\tan \delta_{\mathrm{ws}}$ (Table 2 ).

\section{Dielectric anisotropy of wood}

The dielectric anisotropies, $\varepsilon^{\prime}{ }_{\mathrm{L}}^{\prime} \varepsilon_{\perp}^{\prime}$, $\tan \delta_{\mathrm{L}} / \tan \delta_{\perp}, \varepsilon_{\mathrm{R}}^{\prime} / \varepsilon^{\prime}$, and $\tan \delta_{\mathrm{R}} / \tan \delta_{\mathrm{T}}$, were obtained from the experimental plots in Fig. 6. They are plotted against $\rho_{0}$ for 0 and 11\% MC in Fig. 7, in which the relations estimated from the regression lines in Fig. 6 are also shown as solid lines.

The plots of $\varepsilon^{\prime} \mathrm{L} / \varepsilon^{\prime} \perp$ agreed rather well with the estimated relations (lines) and were concave downward with maxima around $\rho_{0}=0.5 \mathrm{~g} / \mathrm{cm}^{3}$ for both MCs. This agreement indicates that the dielectric parameters are probably almost unaffected by anatomical structures such as the rays because the anatomical structures were not taken into consideration in the dielectric mixture model. The plots of $\tan \delta_{\mathrm{L}} / \tan \delta_{\perp}$ agreed with the estimated line for $11 \% \mathrm{MC}$ while the plots deviated a lot from the line for $0 \% \mathrm{MC}$. This deviation is probably due to the propagation of large measurement error for the attenuation coefficient $\alpha$ (Fig. 5), which may be caused by multiple reflections and scattering of the MMWs by the annual rings of the specimen. The 
lines for both MCs indicate that $\tan \delta_{\mathrm{L}} / \tan \delta_{\perp}$ decreases with $\rho_{0}$.

These findings show that the dielectric anisotropy between the $\mathrm{L}$ and $\perp$ directions can be explained by the dielectric mixture model assuming that wood substance is a dielectric isotropic material and that the pore alignment is represented by the parallel capacitor and Lichtenecker's exponential formulas in the $\mathrm{L}$ and $\perp$ directions. The dielectric isotropy of wood substance implies that there is little influence from the dipole polarization of the $-\mathrm{CH}_{2} \mathrm{OH}$ group in the amorphous region of cellulose on the dielectric parameters of wood substance at $100 \mathrm{GHz}$, because the anisotropy of wood substance is caused by the difference in apparent activation energy of the motion of the group from one site to another between the $L$ and $\perp$ directions [23].

There was a little and almost no variation from unity in $\varepsilon^{\prime}{ }_{\mathrm{R}} / \varepsilon^{\prime}{ }_{\mathrm{T}}$ and $\tan \delta_{\mathrm{R}} / \tan \delta_{\mathrm{T}}$, respectively, over the wide range of $\rho_{0}$ for both MCs. This indicates that the influence of the rays on the dielectric properties in the $\perp$ direction of wood may be negligible and thus strongly suggests that the dielectric parameters are little affected by the anatomical structures. 


\section{Conclusion}

The dielectric parameters for LT specimens of nine species at 0 and $11 \% \mathrm{MC}$ were measured using a free space method at a frequency of $100 \mathrm{GHz}$ under an electric field parallel to $\mathrm{L}$ and $\mathrm{T}$ directions and estimated using a conventional approximation theory [26] in $\mathrm{R}$ direction. The dielectric parameters, i.e., relative dielectric constants and loss tangents, in the T and R directions $(\perp)$ were almost identical and constantly smaller than those in the $\mathrm{L}$ direction. All the dielectric parameters increased with the oven-dry density of wood and were larger at $11 \%$ than $0 \%$ MC. The dielectric parameters in the $\mathrm{L}$ and $\perp$ directions and the dielectric anisotropy between them were fitted to the regression lines based on a dielectric mixture model composed of pores and dielectric isotropic wood substance in which the pore alignment is represented using a parallel capacitor and Lichtenecker's exponential formulas [33-35] in the $\mathrm{L}$ and $\perp$ directions. These findings show that the dielectric anisotropy at $100 \mathrm{GHz}$ is caused by the pore alignment and that the dielectric parameters are almost unaffected by the anatomical structure. Further examination is necessary to clarify the physical interpretation of the Lichtenecker's exponential formula.

The influence of the multiple reflections in the free space method was reduced by covering the receiving waveguide equipped with an absorbent and by using the estimation model taking account of this influence into the amplitude and phase of the MMWs. The measured dielectric parameters were consistent with those obtained by using a conventional waveguide method [26, 32]. This indicates that the free space method was effective for the measurement of the dielectric parameters in the MMW frequency range. Further examination is necessary to clarify the scattering of the MMWs by annual rings of wood.

\section{Acknowledgements}

This work was supported in part by a Grant-in-Aid from the Japan Society for the Promotion of Science for JSPS Fellows (233453) and in part by a Grant-in-Aid from the JSPS (21300329). The authors would like to express their appreciation to Professor Dr. Tadao Nagatsuma of the Graduate School of Engineering Science, Osaka University, who gave us advise on how to adjust the measurement system. 


\section{Reference}

1. Laurinavičius A, Baltrušaitis A, Pranckevičiene V, Ukvalbergienė K (2010) Wood characterization by scanning millimeter wave beam. Mater Sci (Medžiagotyra)16:63-66

2. Oyama Y, Zhen L, Tanabe T, Kagaya M (2009) Sub-terahertz imaging of defects in building blocks. NDT \& E Int 42:28-33

3. Tanaka S, Fujiwara Y, Fujii Y, Okumura S, Togo H, Kukutsu N, Nagatsuma T (2011) Effect of grain direction on transmittance of 100-GHz millimeter wave for hinoki (Chamaecyparis Obtusa). J Wood Sci 57:189-194

4. Hansson L, Lundgren N, Antti AL, Hagman O (2005) Microwave penetration in wood using imaging sensor. Meas 38:15-20

5. James WL, Yen Y-H, King RJ (1985) A microwave method for measuring moisture content, density, and grain angle of wood. Research note FPL-0250

6. Johansson J, Hagman O, Fjellner B-A (2003) Predicting moisture content and density distribution of Scots pine by microwave scanning of sawn timber. J Wood Sci 49:312-316

7. King RJ, Yen YH (1981) Probing amplitude, phase, and polarization of microwave field distributions in real time. IEEE Trans Micro Theory Tech 29:1225-1231

8. Lundgren N, Hagman O, Johansson J (2006) Predicting moisture content and density distribution of Scots pine by microwave scanning of sawn timber II: evaluation of models generated on a pixel level. J Wood Sci 52:39-43

9. Martin P, Collet R, Barthelemy P, Roussy G (1987) Evaluation of wood characteristics: Internal scanning of the material by microwaves. Wood Sci Technol 21:361-371

10. Portala J-F, Ciccotelli J (1992) Nondestructive testing techniques applied to wood scanning. Ind Metrol 2:299-307

11. Schajer GS, Orhan FB (2005) Microwave non-destructive testing of wood and similar orthotropic materials. Subsurface Sensing Technologies and Applications 6:293-313

12. Schajer GS, Orhan FB (2006) Measurement of wood grain angle, moisture content and density using microwaves. Holz als Roh- und Werkstoff 64:483-490

13. Shen J, Schajer G, Parker R (1994) Theory and practice in measuring wood grain angle using microwaves. IEEE Trans Instrum Meas 43:803-809

14. James WL (1963) Electric moisture meters for wood. USDA Forest Service Research Paper FPL-08

15. James WL (1975) Dielectric properties of wood and hardboard: Variation with temperature, frequency, moisture content, and grain orientation. USDA Forest Service Research Paper FPL-245

16. James WL, Hamill DW (1965) Dielectric properties of Douglas-fir. Forest Prod J 15:51-56

17. Kröner K, Pungs L (1952) Zur dielektrischen Anisotropie des Naturholzes im großen Frequenzbereich. Holzforschung 6:13-16

18. Kröner K, Pungs L (1953) Über das Verhalten des dielektrischen Verlustfaktors des Naturholzes im großen Frequenzbereich. Holzforschung 7:12-18

19. Makoviny I (1988) Zur Anisotrpie der Dielektrizitätskonstanten des Holzes in grundlegenden anatomischen Richtungen. Holztechnologie 29:210-213 
20. Nakato K, Kadita S (1954) On the dielectric constant of the oven-dried wood. J Japanese Forestry Soc 36:95-100

21. Nanassy AJ (1970) Overlapping of dielectric relaxation spectra in oven-dry yellow birch at temperatures from 20 to $100^{\circ} \mathrm{C}$. Wood Sci Technol 4:104-121

22. Norimoto M (1976) Dielectric properties of wood. Wood Res Bull Wood Res Inst Kyoto Univ 59/60:106-152

23. Norimoto M, Yamada T (1971) The dielectric properties of wood V, On the dielectric anisotropy of wood. Wood Res Bull Wood Res Inst Kyoto Univ 51:12-32

24. Peyskens E, de Pourcq M, Stevens M, Schalck J (1984) Dielectric properties of softwood species at microwave frequencies. Wood Sci Technol 18:267-280

25. Skaar C (1948) The dielectrical properties of wood at several radio frequencies. N Y State Coll of Forestry, Technical Publication No. 69, pp 1-36

26. Torgovnikov GI (1993) Dielectric properties of Wood and Wood-Based Materials. Springer, Berlin, pp $1-76$

27. Trapp W, Pungs L (1956) Bestimmung der dielektrischen Werte von Cellulose, Glukose und der Zellsubstantz von Naturholz im großen Frequenzbereich 10:65-68

28. Trapp W, Pungs L (1956) Einfluß von Temperatur und Feuchte auf das dielektrische Verhalten von Naturholz im großen Frequenzbereich. Holzforschung 10:144-150

29. Uyemura T (1960) Dielectric properties of woods as the indicator of the moisture. Bull Gov For Exp Sta 119:96-172

30. Ghodgaonkar DK, Varadan VV, Varadan VK (1989) A free-space method for measurement of dielectric constants and loss tangents at microwave frequencies. IEEE Trans Instr Meas 37:789-793

31. Ghodgaonkar DK, Varadan VV, Varadan VK (1990) Free-space measurement of complex permittivity and complex permeability of magnetic materials at microwave frequencies. IEEE Trans Instr Meas 39:387-394

32. Von Hippel AR (1954) Dielectric materials and applications. Wiley, New York, pp 1-438

33. Lichtenecker K (1926) Die Dielektrizitätskonstante natürlicher und künstlicher Mischkörper. Phys Z 27:115-158

34. Lichtenecker K, Rother K (1931) Die Herleitung des logarithmischen Mischungs-gesetzes aus allegemeinen Prinzipien der stationaren Stromung. Phys Z 32:255-260

35. Büchner A (1939) Das Mischköperproblem in der Kondensatortechnik. Wissenschaftliche Veröffentlichungen aus dem Siemens-Konzern 18:84-96

36. Zakri T, Laurent JP, Vauclin M (1998) Theoretical evidence for 'Lichtenecker's mixture formulae' based on the effective medium theory. J Phys D Appl Phys 31:1589-1594

37. Wood Technological Association of Japan (1989) Wood Technological Association of Japan (ed) Nippon nomokuzai, 3rd edn (in Japanese). Wood Technological Association of Japan, Tokyo pp1-101 
[Figure legends]

Fig. 1. Experimental setup of a MMW measurement system arranged in a right-handed Cartesian coordinate system $(x, y, z) .1$. Gunn diode (100 GHz), 2. Isolator, 3. Directional coupler, 4. PIN diode, 5. Phase shifter, 6. Conical horn antenna, 7. Teflon plano-parabolic lens, 8. Specimen, 9. Open-ended rectangular waveguide (inner cross section: $x \times y=2.54 \mathrm{~mm} \times 1.27 \mathrm{~mm}$ ) covered with millimeter wave absorbent except open end, 10. Quadrature phase shifter, 11. Switching frequency generator (100 kHz), 12. Mixer, 13. Lock-in amplifier, 14. IQ-mixer, and 15. Dielectric waveguide. $V_{\mathrm{I}}$ and $V_{\mathrm{Q}}$, output voltages of in-phase (I) and quadrature (Q) components of a MMW signal.

Fig. 2. Relation of voltages, (a) $V_{\mathrm{I}}$ and (b) $V_{\mathrm{Q}}$, to phase controlled by phase shifter, $\varphi$, for hinoki at $\mathrm{MC}=$ $11 \%$ under electric field of MMWs parallel to T direction of specimen. $d$, specimen thickness.

Fig. 3. Relation of phase of MMWs, $\xi$, to products of oven-dry density and thickness of specimen, $\rho_{0} d$, for all species at $11 \% \mathrm{MC}$. The phases for plots surrounded by solid and dotted lines should be larger by $2 \pi$ and $4 \pi \mathrm{rad}$, respectively.

Fig. 4. Relation of attenuation, $\ln P$, and phase shift, $\Delta \xi$, to specimen thickness, $d$, under electric field of MMWs parallel to $\mathrm{L}$ and $\mathrm{T}$ directions.

Fig. 5. Relation of (a) attenuation, $\alpha$, and (b) phase, $\beta$, coefficients to oven-dry density, $\rho_{0}$, for all species under electric field of MMWs parallel to $\mathrm{L}$ and $\mathrm{T}$ directions at 0 and 11\% MC. Error bars represent standard deviations. $\lambda$, wavelength of MMWs, $3 \mathrm{~mm}$.

Fig. 6. Relation of (a) relative dielectric constant, $\varepsilon^{\prime}$, (b) loss tangent, $\tan \delta$, at $0 \% \mathrm{MC}$, (c) relative dielectric constant, $\varepsilon^{\prime}$, and (d) loss tangent, $\tan \delta$, at $11 \% \mathrm{MC}$ to $\rho_{0}$ for all species under electric field parallel to $\mathrm{L}, \mathrm{T}$, and R directions. Error bars represent standard deviations for plots, solid black and gray lines are regression lines obtained from Eqs. (5) and (6), respectively, and dotted lines were measured by a waveguide method ((a) and (b)) and predicted (c), respectively [26].

Fig. 7. Relation of ratios (a) $\varepsilon^{\prime}{ }_{\mathrm{L}}^{\prime} / \varepsilon^{\prime} \perp$ and $\varepsilon^{\prime}{ }_{\mathrm{R}} / \varepsilon^{\prime} \mathrm{T}$, and (b) $\tan \delta_{\mathrm{L}} / \tan \delta_{\perp}$ and $\tan \delta_{\mathrm{R}} / \tan \delta_{\mathrm{T}}$ to $\rho_{0}$. Error bars represent standard deviations for plots. 


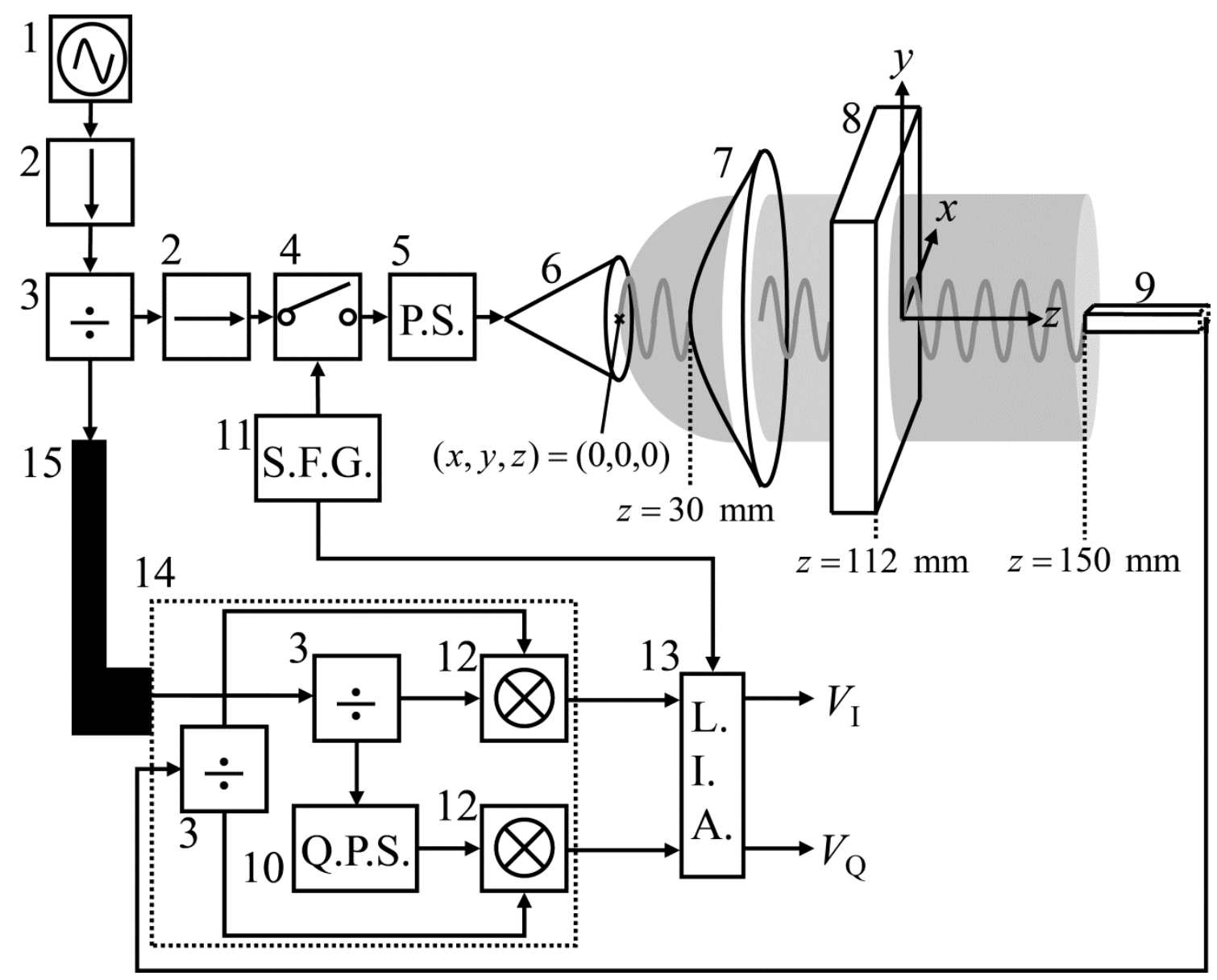

Fig. 1 


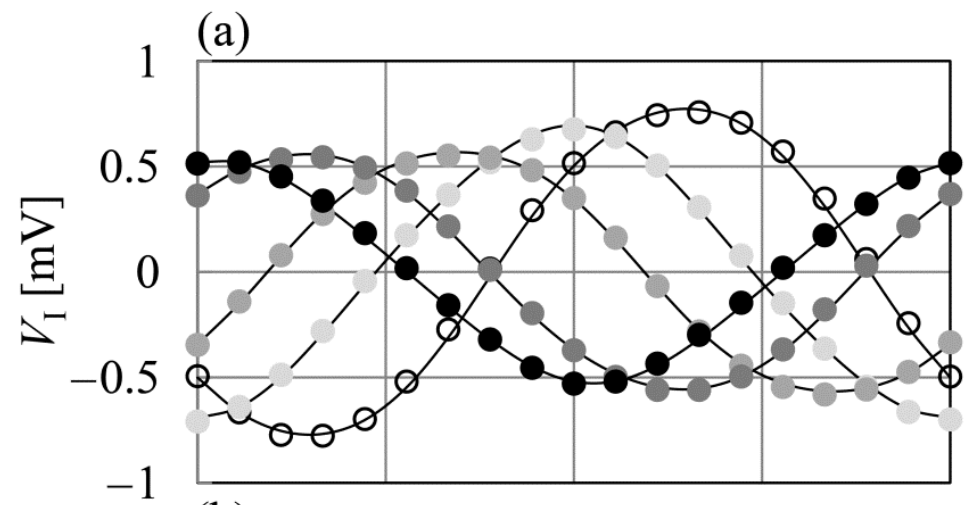

\begin{tabular}{|rr|}
\hline$\circ$ & No specimen \\
& $d=0.22 \mathrm{~cm}$ \\
0 & $0.40 \mathrm{~cm}$ \\
- & $0.60 \mathrm{~cm}$ \\
$0.82 \mathrm{~cm}$ \\
\hline
\end{tabular}

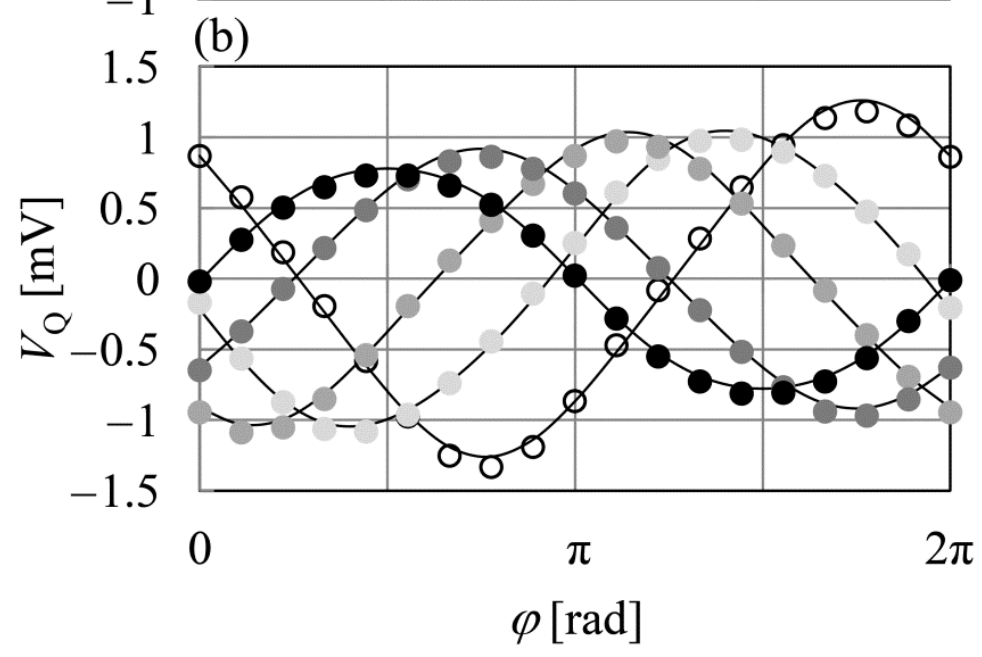

Fig. 2 


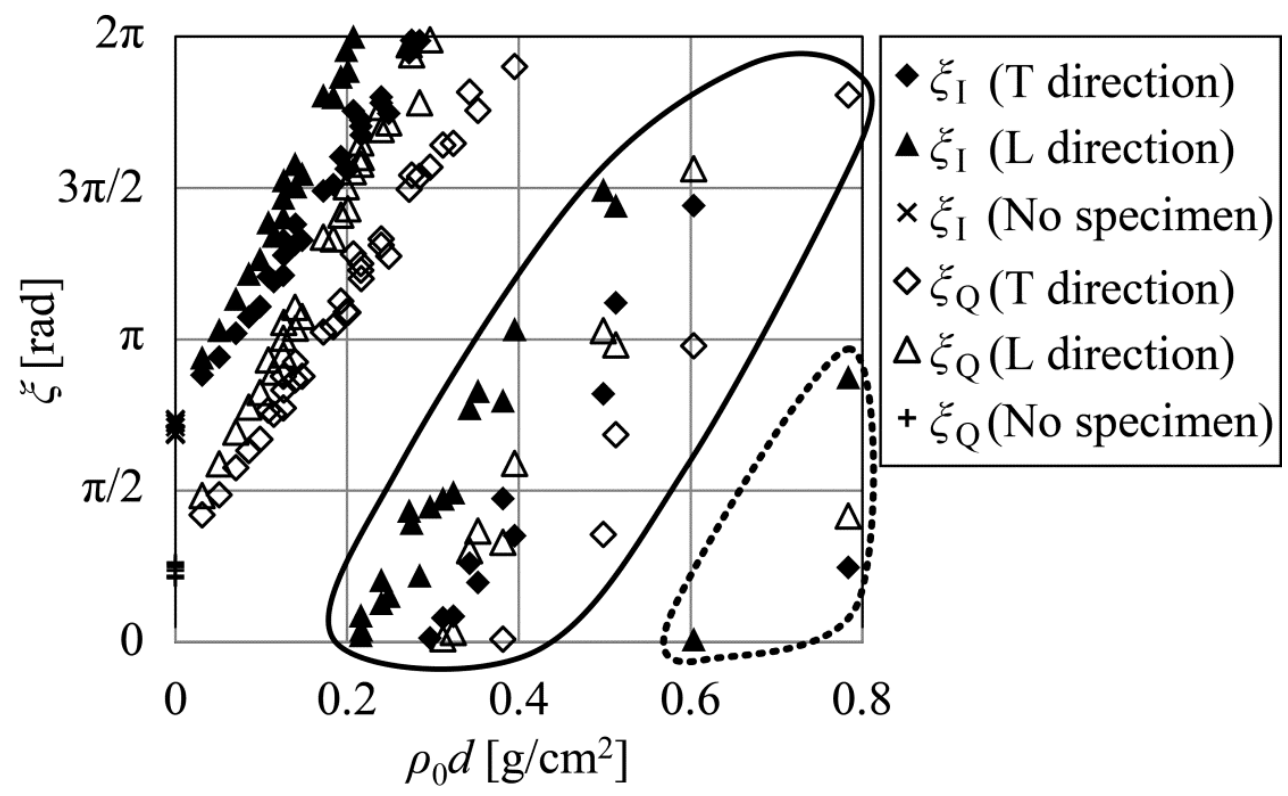

Fig. 3 

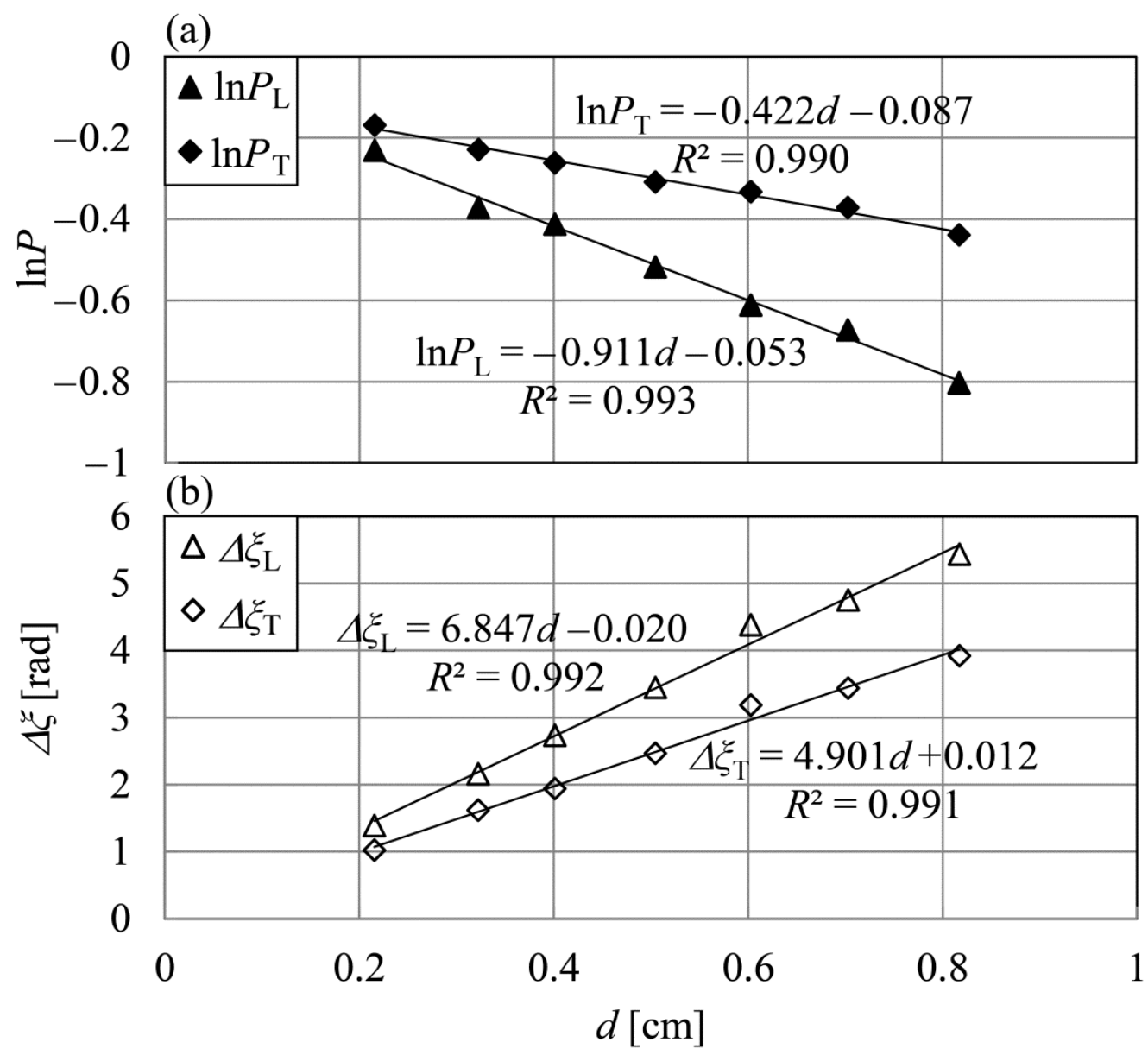

Fig. 4 

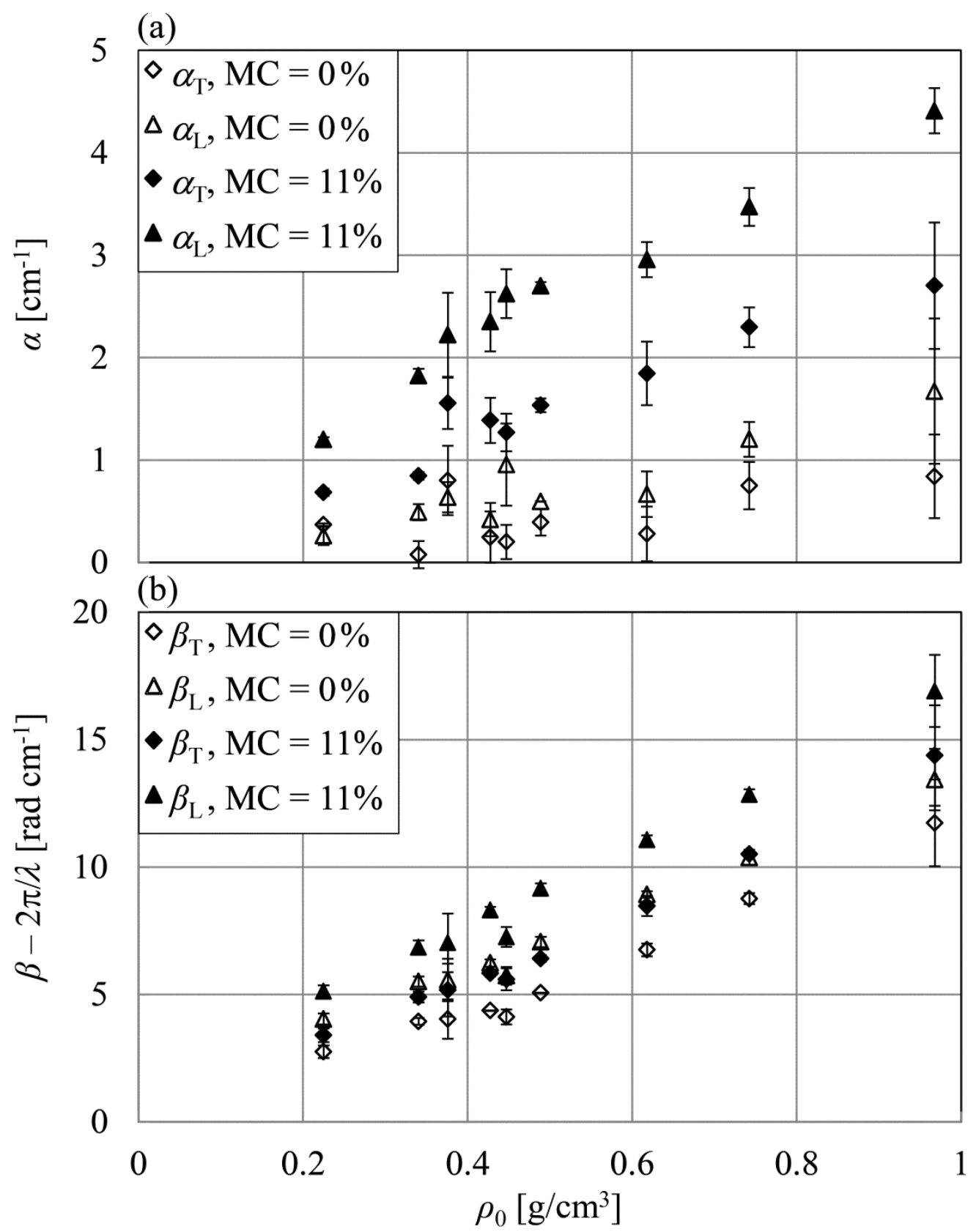

Fig. 5 


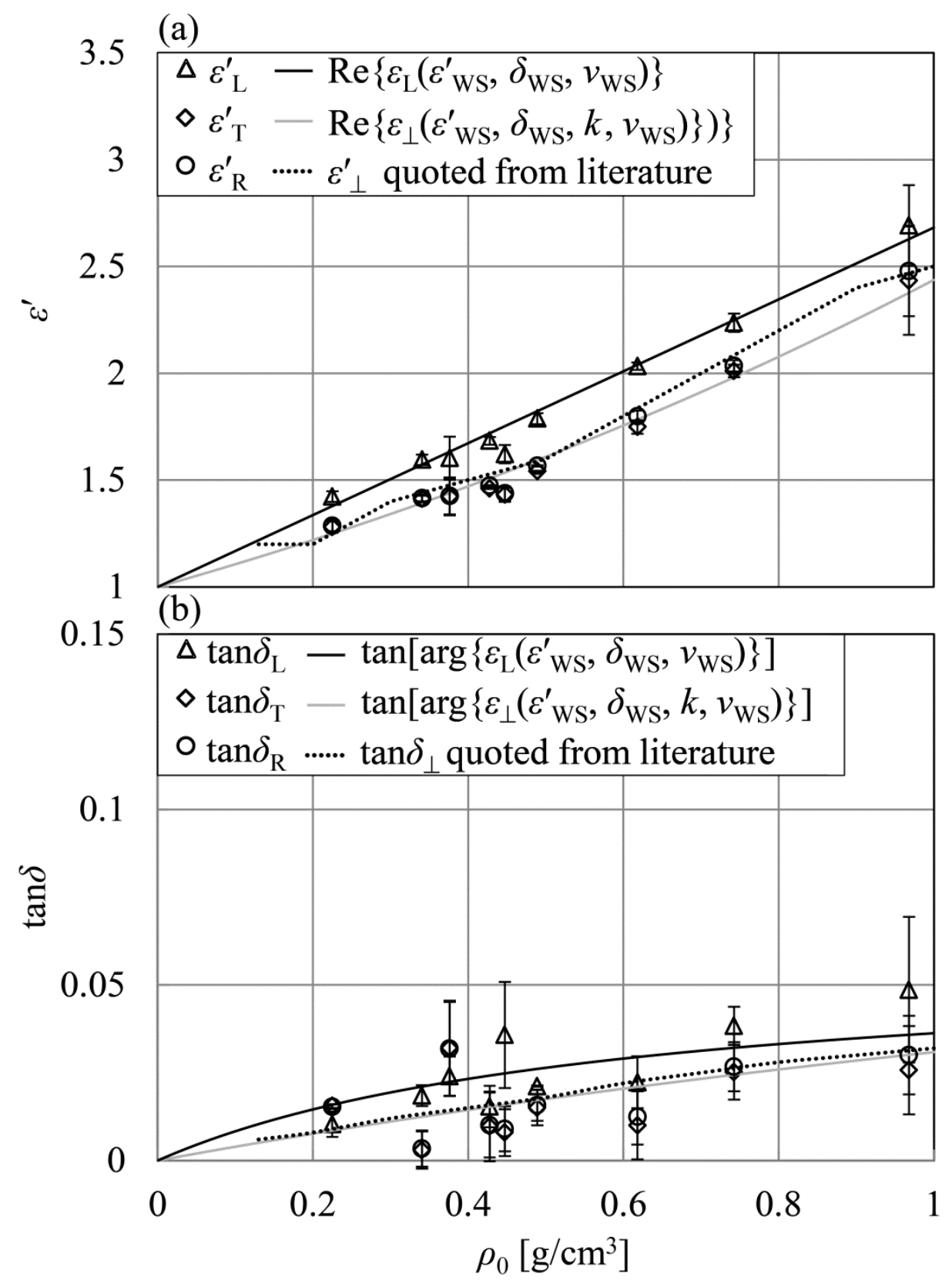

Fig. 6 (a),(b) 

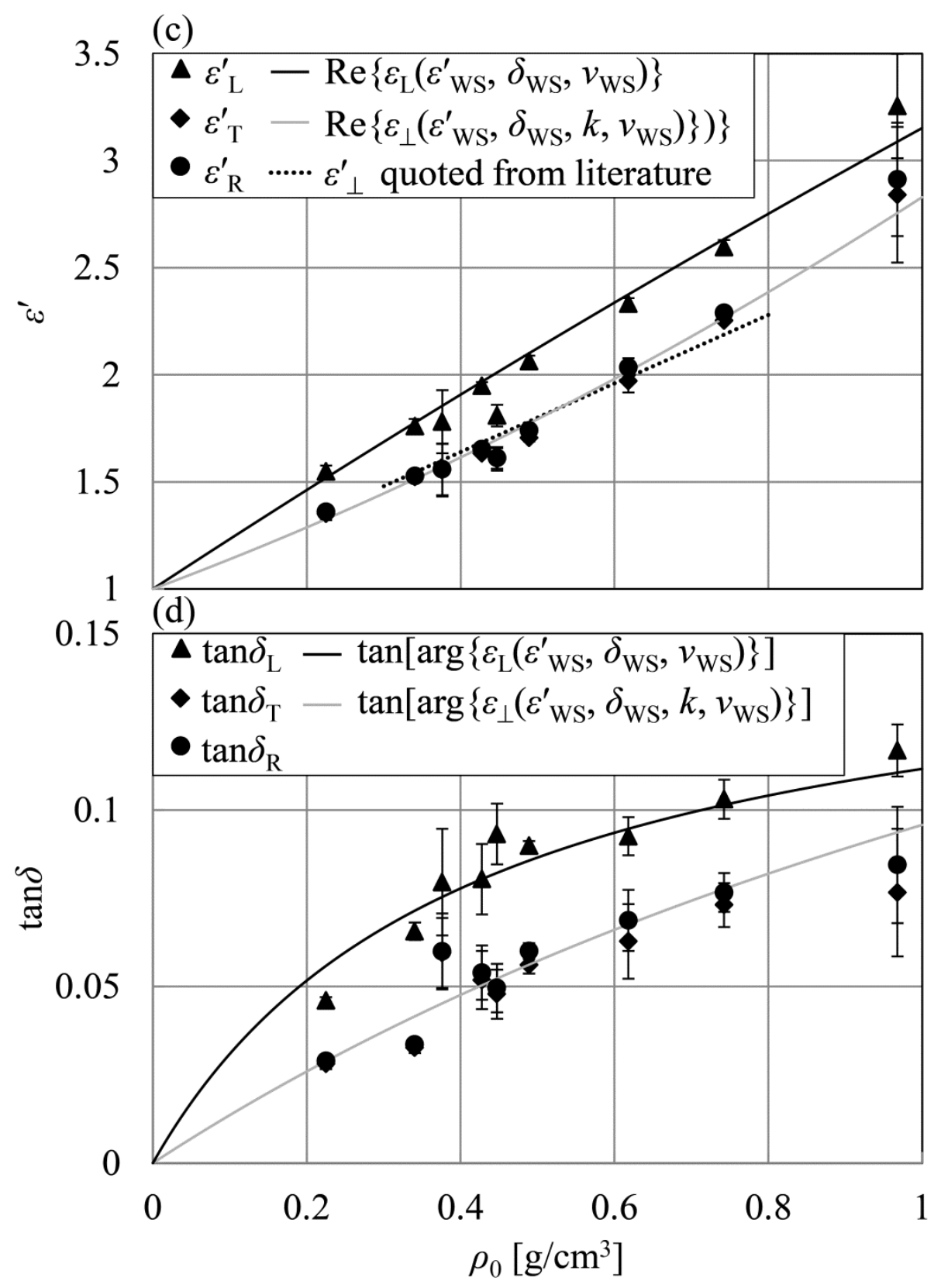

Fig. 6 (c),(d) 
(a)

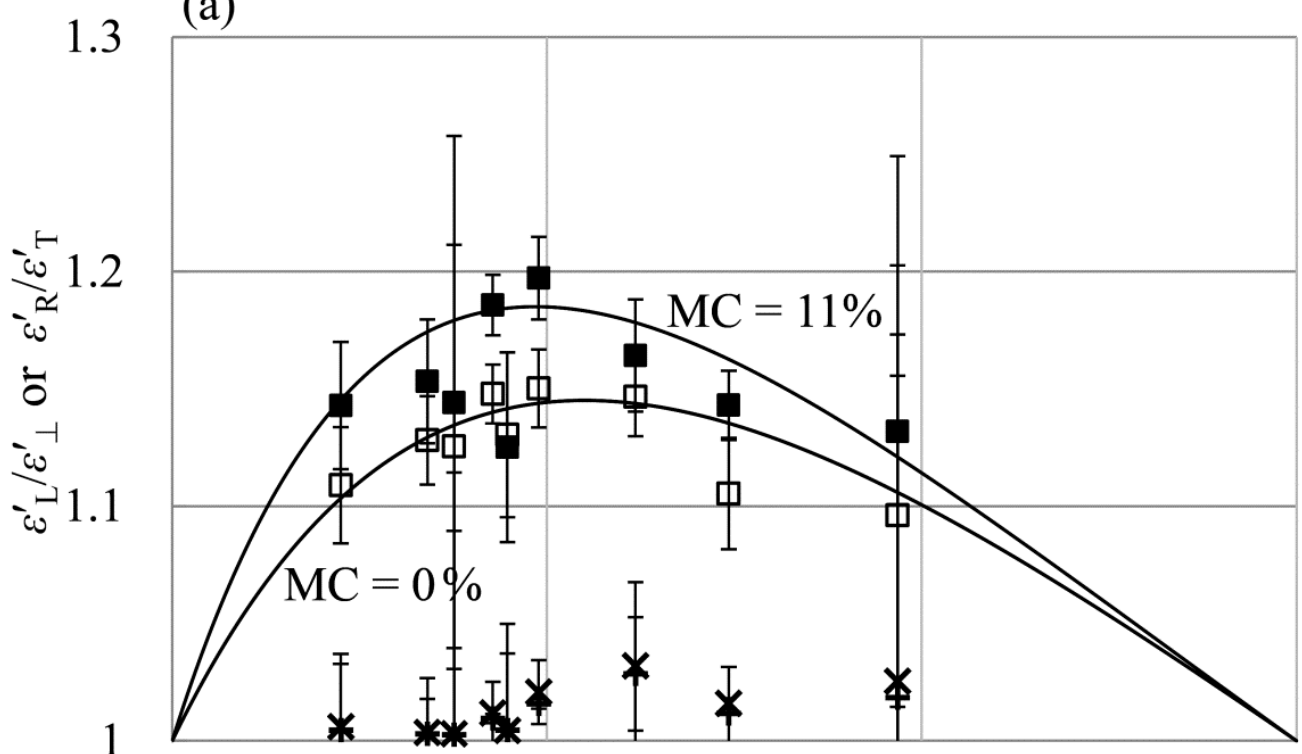

(b)

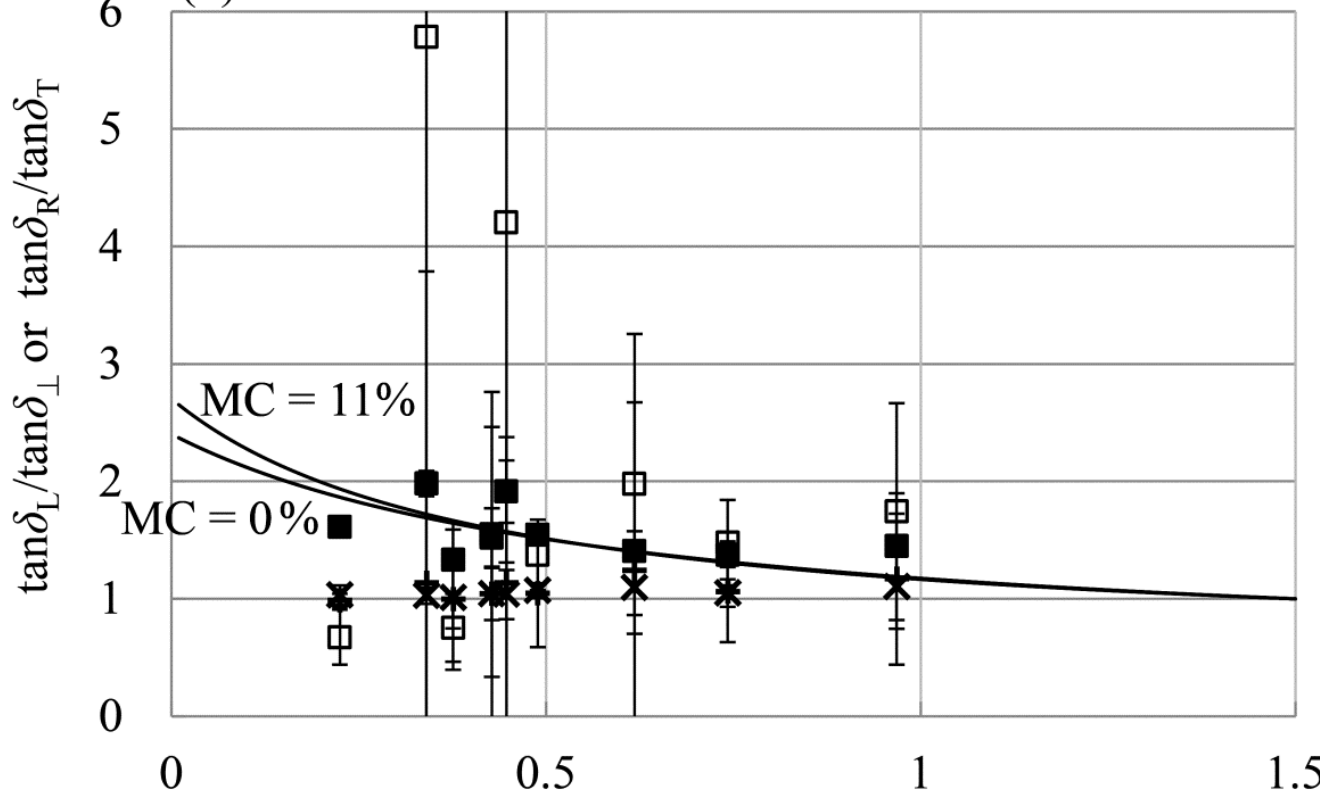

$\rho_{0}\left[\mathrm{~g} / \mathrm{cm}^{3}\right]$

$\square \varepsilon_{\mathrm{L}}^{\prime} / \varepsilon_{\perp}^{\prime}, \tan \delta_{\mathrm{L}} / \tan \delta_{\perp}(\mathrm{MC}=0 \%)+\varepsilon_{\mathrm{R}}^{\prime} / \varepsilon_{\mathrm{T}}^{\prime}, \tan \delta_{\mathrm{R}} / \tan \delta_{\mathrm{T}}(\mathrm{MC}=0 \%)$

- $\varepsilon_{\mathrm{L}}^{\prime} / \varepsilon_{\perp}^{\prime}, \tan \delta_{\mathrm{L}} / \tan \delta_{\perp}(\mathrm{MC}=11 \%) \times \varepsilon_{\mathrm{R}}^{\prime} / \varepsilon_{\mathrm{T}}^{\prime}, \tan \delta_{\mathrm{R}} / \tan \delta_{\mathrm{T}}(\mathrm{MC}=11 \%)$

$\left.\left.-\operatorname{Re}\left\{\varepsilon_{\mathrm{L}}\left(\varepsilon_{\mathrm{WS}}^{\prime}, \delta_{\mathrm{WS}}, v_{\mathrm{WS}}\right)\right\} / \operatorname{Re}\left\{\varepsilon_{\perp}\left(\varepsilon_{\mathrm{WS}}^{\prime}, \delta_{\mathrm{WS}}, k, v_{\mathrm{WS}}\right)\right\}\right)\right\}$, $\tan \left[\arg \left\{\varepsilon_{\mathrm{L}}\left(\varepsilon_{\mathrm{WS}}^{\prime}, \delta_{\mathrm{WS}}, v_{\mathrm{WS}}\right)\right\}\right] / \tan \left[\arg \left\{\varepsilon_{\perp}\left(\varepsilon_{\mathrm{WS}}^{\prime}, \delta_{\mathrm{WS}}, k, v_{\mathrm{WS}}\right)\right\}\right]$

Fig. 7 
Table 1. Oven-dry densities and volume fractions of rays for all specimens.

\begin{tabular}{llll}
\hline Species & & $\begin{array}{l}\text { Oven-dry density, } \\
\rho_{0}\left[\mathrm{~g} / \mathrm{cm}^{3}\right]\end{array}$ & $\begin{array}{l}\text { Volume fraction of rays, } \\
v_{\mathrm{r}}\end{array}$ \\
\hline \multirow{2}{*}{ Softwood } & Hinoki & $0.34 \pm 0.01^{\mathrm{b})}$ & 0.023 \\
& Sugi & $0.37 \pm 0.08$ & 0.020 \\
& Akamatsu & $0.45 \pm 0.05$ & 0.034 \\
\hline \multirow{2}{*}{ Ring-porous } & Kiri & $0.23 \pm 0.04$ & 0.041 \\
hardwood & Kuri & $0.43 \pm 0.01$ & 0.062 \\
& Keyaki & $0.74 \pm 0.01$ & 0.105 \\
\hline \multirow{2}{*}{ Diffuse-porous } & Tochinoki & $0.49 \pm 0.01$ & 0.099 \\
hardwood & Buna & $0.62 \pm 0.02$ & 0.175 \\
& Isunoki & $0.97 \pm 0.06$ & 0.174 \\
\hline
\end{tabular}

a) Literature values [37].

b) Standard deviation. 
Table 2. Dielectric parameters of wood substance, $\varepsilon^{\prime}$ ws and $\tan \delta_{\mathrm{Ws}}$, and coefficient reflecting porous structure of wood in transverse direction, $k$.

\begin{tabular}{rrrc}
\hline $\mathrm{MC}[\%]$ & $\varepsilon^{\prime} \mathrm{Ws}$ & $\tan \delta \mathrm{Ws}$ & $k$ \\
\hline 0 & 3.5 & 0.04 & 0.30 \\
11 & 4.1 & 0.12 & 0.30
\end{tabular}

